\title{
Activities Forgone because of Chronic Breathlessness: A Cross-Sectional Population Prevalence Study
}

Slavica Kochovska, BA (Hons), MA (Hons 1), PhD, ${ }^{1,2}$ Sungwon Chang, PhD, ${ }^{1,2}$

Deidre D. Morgan BAppSc (OT), MCSc (OT), PhD, ${ }^{3}$ Diana Ferreira, MD, MPC, ${ }^{4}$ Manraaj Sidhu, BSci (Hon), BMSci, ${ }^{2}$

Rayan Saleh Moussa, PhD, ${ }^{5}$ Miriam J. Johnson, MD, FRCP, MRCP, MBChB (Hons), ${ }^{6}$

Magnus Ekström, MD, PhD, 7 and David C. Currow, BMed, MPH, PhD, FRACP, FAHMS 1,2,6,* $^{1}$

\begin{abstract}
Background: Chronic breathlessness is a prevalent disabling syndrome affecting many people for years. Identifying the impact of chronic breathlessness on people's activities in the general population is pivotal for designing symptom management strategies.

Objective: This study aimed to evaluate the association between chronic breathlessness and activities respondents identify can no longer be undertaken ("activities forgone").

Design: This population-based cross-sectional online survey used a market research company's database of 30,000 registrants for each sex, generating the planned sample size-3000 adults reflecting Australia's 2016 Census by sex, age group, state of residence, and rurality.

Setting/Subjects: The population of focus $(n=583)$ reported a modified Medical Research Council (mMRC) breathlessness scale $\geq 1$ and experienced this breathlessness for $\geq 3$ months.

Measurements: Activities forgone were categorized by mMRC using coding derived from the Dyspnea Management Questionnaire domains. Activities were classified as "higher/lower intensity" using Human Energy Expenditure scale. Results: Respondents were male 50.3\%; median age 50.0 (IQR 29.0); with 66\% living in metropolitan areas; reporting 1749 activities forgone. For people with mMRC $1(n=533), 35 \%$ had not given up any activity, decreasing to $9 \%$ for mMRC $2(n=38)$ and 3\% for mMRC 3-4 ( $n=12)$. Intense sport (e.g., jogging and bike riding) was the top activity forgone: $42 \%$ (mMRC 1), 32\% (mMRC 2), and 36\% (mMRC 3-4). For respondents with mMRC 3-4, the next most prevalent activities forgone were "sexual activities" (14\%), "lower intensity sports" (11\%), and "other activities" (11\%). Conclusions: People progressively reduce a wide range of activities because of their chronic breathlessness.
\end{abstract}

Keywords: breathlessness; dyspnea; symptom; symptom assessment

\section{Introduction}

Chronic breathlessness is a disabling syndrome ${ }^{1}$ affecting $>2.6 \%$ of the population daily, often for years. ${ }^{2}$ Function is compromised, ${ }^{3}$ creating a downward cycle of deconditioning, ${ }^{4}$ social isolation ${ }^{5,6}$ and physical dependence. Clinicians under-recognize the impact chronic breathlessness has on peoples' lives, ${ }^{7,8}$ often instead focusing on the underlying disease(s). ${ }^{9}$ Identifying the impact of chronic breathlessness on people's activities in the general population is pivotal for

${ }^{1}$ IMPACCT, Faculty of Health, University of Technology Sydney, Ultimo, New South Wales, Australia.

${ }^{2}$ Australian national Palliative Care Clinical Studies Collaborative, Faculty of Health, University of Technology Sydney, Ultimo, New South Wales, Australia.

${ }^{3}$ Flinders University, Palliative and Supportive Services, RePaDD, Bedford Park, South Australia, Australia.

${ }^{4}$ Flinders University, Palliative and Supportive Services, Bedford Park, South Australia, Australia.

${ }^{5}$ Cancer Symptom Trials, Faculty of Health, University of Technology Sydney, Ultimo, New South Wales, Australia.

${ }^{6}$ Wolfson Palliative Care Research Centre, University of Hull, Hull, United Kingdom.

${ }^{7}$ Division of Respiratory Medicine \& Allergology, Department of Clinical Sciences, Lund University, Lund, Sweden.

*Address correspondence to: David C. Currow, BMed, MPH, PhD, FRACP, FAHMS, IMPACCT, Faculty of Health, University of Technology Sydney, PO Box 123, Ultimo 2007, New South Wales, Australia, E-mail: david.currow@uts.edu.au

(C) Slavica Kochovska et al., 2020; Published by Mary Ann Liebert, Inc. This Open Access article is distributed under the terms of the Creative Commons License (http://creativecommons.org/licenses/by/4.0), which permits unrestricted use, distribution, and reproduction in any medium, provided the original work is properly cited. 
designing and promoting self-management and other symptom treatment strategies, and to help ultimately reduce unplanned health service utilization. ${ }^{10,11}$

The association between chronic breathlessness and impaired function has been demonstrated, but the range of the activities forgone as chronic breathlessness worsens has not been systematically captured at a population level. Describing any impact on populations (recruited independently of people's contact with health services) is important, given that chronic breathlessness remains largely invisible to health systems. ${ }^{8,10}$

This study aimed to evaluate the association between chronic breathlessness and the activities respondents identify can no longer be undertaken: activities of daily living and those activities that contribute to life's richness.

\section{Materials and Methods}

This population-based cross-sectional cohort study used an online survey (November 2018). A market research company's database of up to 30,000 registrants for each sex generated the preplanned sample of 3000 responses representative of Australia's 2016 Census population ${ }^{12}$ by sex, 10 year age group, state/territory of residence, and rurality. Consenting adults $(\geq 18$ years) were eligible, and screened out if cells created using these four demographic domains were already filled by earlier respondents. No identifying information was collected. This community survey was governed by the Australian Market and Social Research Society code of conduct that aligns with best global industry standards for the conduct of social online research surveys and quantitative data collection. Consent from registrants was obtained at two separate time points: at the time of joining the database and at the time of participating in this particular survey.

The modified Medical Research Council (mMRC) breathlessness five-point ordinal scale $^{13}$ assessed chronic breathlessness. Higher scores reflect less function before breathlessness limits exertion. Respondents with $\mathrm{mMRC} \geq 1$ were asked to nominate three activities they had given up because of their chronic breathlessness ("activities forgone").

A coding frame combined responses to the "activities forgone" question with the Dyspnea Management Questionnaire (DMQ-30) "self-efficacy for activity" domain $^{14}$ and the DMQ Computer Adaptive Test (DMQ-CAT) "activity avoidance" and "activity selfefficacy" domains. ${ }^{15}$ This is a validated measure for breathlessness in adults with chronic obstructive pul- monary disease (COPD). Classifying activities as "higher/lower intensity" (where applicable) followed Human Energy Expenditure scales. ${ }^{16}$

The population of particular interest for the analysis were defined by having an $\mathrm{mMRC} \geq 1$ for longer than three months duration $(n=583 / 3000)$. Activities forgone were categorized by mMRC scores. No data were imputed. The study is presented within the CHERRIES framework for online surveys. ${ }^{17}$

\section{Results}

Study participants were male $50.3 \%$; median age 50.0 (IQR 29.0); with 66\% living in metropolitan areas (Table 1). They provided 1749 coded activities forgone (Table 2). Most people $(n=533 ; 91 \%)$ had $\mathrm{mMRC}=1$, nominating 1599 activities forgone.

For people with mMRC $1(n=533), 35 \%$ of responses indicated that they had not given up any activity, decreasing to $9 \%$ for people with mMRC $2(n=38)$

Table 1. Domains Measured for Respondents to an Internet Survey on Breathlessness $(n=3000)$ Described by the Modified Medical Research Council Breathlessness Scale

\begin{tabular}{|c|c|c|c|c|}
\hline \multirow[b]{2}{*}{ Domain measured } & \multicolumn{4}{|c|}{$\begin{array}{l}\text { Breathlessness (mMRC } 1-4) \\
\text { and } \geq 3 \text { months duration }(n=583)\end{array}$} \\
\hline & $\begin{array}{l}\text { mMRC } 1 \\
(n=533)\end{array}$ & $\begin{array}{c}\mathrm{mMRC} 2 \\
(\mathrm{n}=38)\end{array}$ & $\begin{array}{l}\mathrm{mMRC} 3-4 \\
(\mathrm{n}=12)\end{array}$ & $\begin{array}{c}\text { Total } \\
(n=583)\end{array}$ \\
\hline \multicolumn{5}{|l|}{ Age } \\
\hline Mean (SD) & $50.6(15.9)$ & $46.8(16.0)$ & $46.6(20.6)$ & $50.3(16.1)$ \\
\hline Med (IQR) & $51.0(28.0)$ & $44.5(31.0)$ & $40.5(43.0)$ & $50.0(29.0)$ \\
\hline $18-34$ & $115(21.6)$ & $11(28.9)$ & $5(41.7)$ & $131(22.5)$ \\
\hline $35-44$ & 99 (18.6) & $8(21.1)$ & $1(8.3)$ & 108 (18.5) \\
\hline $45-54$ & 85 (15.9) & $8(21.1)$ & $1(8.3)$ & $94(16.1)$ \\
\hline $55-64$ & 99 (18.6) & $2(5.3)$ & $1(8.3)$ & $102(17.5)$ \\
\hline 65 and older & $135(25.3)$ & $9(23.7)$ & $4(33.3)$ & $148(25.4)$ \\
\hline Female & $268(50.3)$ & $19(50)$ & $3(25)$ & $290(49.7)$ \\
\hline Male & $265(49.7)$ & $19(50)$ & $9(75)$ & $293(50.3)$ \\
\hline Greater capital city & $355(66.6)$ & $21(55.3)$ & $7(58.3)$ & $383(65.7)$ \\
\hline Rest of state/territory & $160(30)$ & $16(42.1)$ & $5(41.7)$ & $181(31)$ \\
\hline No response & $18(3.4)$ & $1(2.6)$ & $0(0)$ & $19(3.3)$ \\
\hline Current smoker & $33(6.2)$ & $3(7.9)$ & $2(16.7)$ & $38(6.5)$ \\
\hline Former smoker & $160(30)$ & $12(31.6)$ & $5(41.7)$ & $177(30.4)$ \\
\hline Never smoked & $293(55)$ & $21(55.3)$ & $4(33.3)$ & $318(54.5)$ \\
\hline Prefer not to say & $2(0.4)$ & $0(0)$ & $1(8.3)$ & $3(0.5)$ \\
\hline No response & $45(8.4)$ & $2(5.3)$ & $0(0)$ & $47(8.1)$ \\
\hline $\begin{array}{c}\text { No anxiety or } \\
\text { depression }\end{array}$ & 418 (78.4) & $22(57.9)$ & $8(66.7)$ & $448(76.8)$ \\
\hline Anxiety only & $20(3.8)$ & $4(10.5)$ & $0(0)$ & $24(4.1)$ \\
\hline Depression only & $37(6.9)$ & $3(7.9)$ & $2(16.7)$ & $42(7.2)$ \\
\hline $\begin{array}{l}\text { Anxiety and } \\
\text { depression }\end{array}$ & $56(10.5)$ & $9(23.7)$ & $1(8.3)$ & $66(11.3)$ \\
\hline No response & $2(0.4)$ & $0(0)$ & $1(8.3)$ & $3(0.5)$ \\
\hline AKPS $100-70$ & $520(97.6)$ & $32(84.2)$ & $10(83.3)$ & $562(96.4)$ \\
\hline AKPS $\leq 60$ & $12(2.3)$ & $6(15.8)$ & $1(8.3)$ & $19(3.3)$ \\
\hline Unable to determine & $1(0.2)$ & $0(0)$ & $1(8.3)$ & $2(0.3)$ \\
\hline
\end{tabular}

AKPS, Australia-modified Karnofsky Performance Scale; mMRC, modified Medical Research Council. 
Table 2. Activities Forgone Nominated by Respondents with Self-Reported Chronic Breathlessness (mMRC $\geq 1$ for $\geq 3$ Months) in a General Population Sample $(n=583)$

\begin{tabular}{|c|c|c|c|c|}
\hline \multirow[b]{2}{*}{ Activities forgone } & \multicolumn{4}{|c|}{ Chronic breathlessness (mMRC $\geq 1$ and $\geq 3$ months duration) ( $n=583$ ) } \\
\hline & $\begin{array}{l}\text { Total nominated } \\
\text { responses }(n=1749)^{a}\end{array}$ & $\begin{array}{c}\text { mMRC } 1 \\
(n=1599)^{a}\end{array}$ & $\begin{array}{l}\mathrm{mMRC} 2 \\
(n=114)^{\mathrm{a}}\end{array}$ & $\begin{array}{c}\mathrm{mMRC} 3-4 \\
(n=36)^{\mathrm{a}}\end{array}$ \\
\hline No trouble & $575(33 \%)$ & $564(35 \%)$ & $10(9 \%)$ & $1(3 \%)$ \\
\hline Sports (higher intensity) & $715(41 \%)$ & $665(42 \%)$ & $37(32 \%)$ & $13(36 \%)$ \\
\hline Sexual activities & $40(2 \%)$ & $30(2 \%)$ & $5(4 \%)$ & $5(14 \%)$ \\
\hline Sports (lower intensity) & $57(3 \%)$ & $36(2 \%)$ & $17(15 \%)$ & $4(11 \%)$ \\
\hline Other & $98(6 \%)$ & $83(5 \%)$ & $11(10 \%)$ & $4(11 \%)$ \\
\hline Gardening/doing yard work & $68(4 \%)$ & $57(4 \%)$ & $8(7 \%)$ & $3(8 \%)$ \\
\hline Strenuous/physical everyday activities & $39(2 \%)$ & $32(2 \%)$ & $5(4 \%)$ & $2(6 \%)$ \\
\hline Hobbies & $20(1 \%)$ & $14(1 \%)$ & $4(4 \%)$ & $2(6 \%)$ \\
\hline Household chores & $47(3 \%)$ & $39(2 \%)$ & $7(6 \%)$ & $1(3 \%)$ \\
\hline Work (lower intensity) & $24(1 \%)$ & $18(1 \%)$ & $5(4 \%)$ & $1(3 \%)$ \\
\hline Caregiving responsibilities for other people/pets & $23(1 \%)$ & $21(1 \%)$ & $2(2 \%)$ & $0(0 \%)$ \\
\hline Shopping (e.g., groceries) & $13(1 \%)$ & $11(1 \%)$ & $2(2 \%)$ & $0(0 \%)$ \\
\hline Visiting friends or family in their home (going out, socializing) & $6(0 \%)$ & $5(0 \%)$ & $1(1 \%)$ & $0(0 \%)$ \\
\hline Work (higher intensity) & $19(1 \%)$ & $19(1 \%)$ & $0(0 \%)$ & $0(0 \%)$ \\
\hline Driving & $5(0 \%)$ & $5(0 \%)$ & $0(0 \%)$ & $0(0 \%)$ \\
\hline Personal care (e.g., getting dressed, showering, and bathing) & $0(0 \%)$ & $0(0 \%)$ & $0(0 \%)$ & $0(0 \%)$ \\
\hline Traveling/holidays & $0(0 \%)$ & $0(0 \%)$ & $0(0 \%)$ & $0(0 \%)$ \\
\hline
\end{tabular}

a Respondents $(n=583)$ were able to nominate up to three activities that have been impacted by their breathlessness in response to the question "Please describe the three most important things that you have had to give up because of your shortness of breath."

'Nominated responses include Nothing/Hasn't given up anything but has slowed down or dealt with it/Don't know/No response.

and 3\% for people with mMRC 3-4 ( $n=12$; Table 2). Intense sport (e.g., running, jogging, and bike riding) was the top activity forgone indicated in $42 \%$ (mMRC 1), 32\% (mMRC 2), and 36\% (mMRC 3-4) of responses. This was followed by "other activities" (e.g., volunteering and getting into the car) (5\%) and "gardening/doing yard work" (4\%) for mMRC 1; and "lower intensity sports" (15\%) and "other activities" (10\%) for mMRC 2. For respondents with mMRC $3-4$, the second most nominated activity forgone was "sexual activities" (14\%), followed by "lower intensity sports" (11\%) and "other activities" (11\%).

\section{Discussion}

This population-based study of people with chronic breathlessness (most of whom would attribute their breathlessness to a respiratory cause) ${ }^{18}$ paints a picture of progressive limitations in activities as the syndrome worsens, with more strenuous activities first affected. At every level of worsening chronic breathlessness, activities of daily living become more difficult as do household chores such as gardening. The magnitude of change is consistent with previous findings showing that $>50 \%$ of community-dwelling people aged $\geq 70$ years live with breathlessness that is severe enough to restrict their activities ${ }^{3}$ and, sadly, contribute to mortality predictions. ${ }^{19}$

Hobbies and recreational activities seem to be most commonly affected by chronic breathlessness. Viewed in the context of Maslow's hierarchy of needs, ${ }^{20}$ people give up higher tier activities early, but this progresses for many people to basics of day-to-day existence, including household chores. Breathlessness impinges on the ability to perform activities outside of the home earlier than in-home activities, ${ }^{21}$ reflecting a shrinking LifeSpace $^{22}$ and increasing social isolation, with potential implications for caregivers and changing roles within the household. Given the known relationship between social isolation and psychological morbidity (also associated with chronic breathlessness), ${ }^{23}$ this may be a target for an intervention such as social prescribing. ${ }^{24}$

Sexual activity diminishes for people with most severe chronic breathlessness (mMRC 3-4). This is consistent with results from a population study that has shown an association between chronic breathlessness and the prevalence and duration of sexual inactivity in people aged $\geq 65$ years. ${ }^{25}$ Sexual function and sexual well-being are important aspects of personhood across the age spectrum, including for people with chronic progressive illnesses and life-limiting illnesses. ${ }^{26-28} \mathrm{~A}$ better understanding of the sexual health of people with chronic breathlessness (and their partners) could help clinicians to proactively help people to optimize their sexual activities. ${ }^{3}$ Eliciting this impact in clinical consultations is critical in ensuring patient-centered communication. $^{29-32}$

Actively avoiding things that cause breathlessness may lead patients to underestimate the severity of 
their chronic breathlessness. ${ }^{7}$ Developing a conversation around the impact of the symptom will help to redress known under-reporting by patients and caregivers. ${ }^{33}$ Although not explicitly asked in this study, responses indicated that people may be reducing (rather than stopping) their daily activities or not enjoying participating in such activities because of their chronic breathlessness.

A limitation is the cross-sectional design that evaluates associations but limits causal inference. The impact of chronic breathlessness on activities was selfreported, with no objective verification. By sampling against key demographic parameters to reflect directly the population seen in the national census (and, therefore, not limited by case finding through having contact with health services), the findings are likely to be generalizable to the whole population. The quota sampling method enables replication for other populations by setting identical parameters. The online delivery of the survey, however, may have introduced bias toward participants who are more technologically adept, educated, or from higher socioeconomic strata, thus limiting the generalizability to the population as a whole.

The present findings have several implications. Current history taking for people with chronic conditions often fails to identify and assess the impact of the symptom, ${ }^{34}$ partly due to inadequate clinical enquiry, and partly due to under-reporting by people who have reduced or forgone activities often as that would have been part of their lives previously. This highlights the need for a more effective and systematic assessment of chronic breathlessness, including its presence, severity, and impact on everyday lives. Timely and accurate identification of the impact of the symptom, and routine evaluation over the course of the illness, will facilitate more targeted self-management options for people who live with this symptom. ${ }^{11,21,35}$ At the health system level, systematic screening and assessment may help to reduce the unplanned use of primary and secondary health care, including acute-on-chronic breathlessness presentations to emergency departments and hospital admissions. ${ }^{10,36-39}$

Future therapeutic interventions should aim to improve people's ability to perform activities both for basic self-care, and to enrich life, reduce/prevent social isolation, and its impact on mental well-being; and to stop and/or reverse deconditioning. ${ }^{40,41}$ Allied health such as occupational therapists and physiotherapists play a key role in optimizing function in this setting.
The impact on caregivers should not be underestimated. As people reduce or cease activities, caregivers will be required to provide increasing physical and psychological care. Equally, this raises questions about providing services for people who may not have a caregiver as they live with an increasing functional impairment due to chronic breathlessness.

\section{Acknowledgments}

The research team thanks the respondents for their time and participation. We thank Research Profile for facilitating this project, especially Spike Games and Lavindi Wickramasooriya. We are grateful to Debbie Marriott and Linda Brown for their expert assistance in bringing this project to fruition.

\section{Funding Information}

This research was funded by discretionary funds held by the academic team at IMPACCT (Improving Palliative, Aged and Chronic Care through Clinical Research and Translation), University of Technology Sydney.

\section{Author Disclosure Statement}

No competing financial interests exist.

\section{References}

1. Johnson MJ, Yorke J, Currow DC: A delphi process defining 'chronic breathlessness syndrome': A distinct clinical entity. Eur Respir J 2016;48 (Suppl 60):PA3754

2. Currow DC, Plummer J, Crockett A, Abernethy AP: A community population survey of prevalence and severity of dyspnoea in adults. J Pain Symptom Manage 2009;38:533-545.

3. Johnson MJ, Bland JM, Gahbauer E, et al.: Breathlessness in elderly adults during the last year of life sufficient to restrict activity. Prevalence, pattern, and associated factors. J Am Geriatr Soc 2016;64:73-80.

4. Pitta F, Troosters T, Spruit MA, et al.: Characteristics of physical activities in daily life in chronic obstructive pulmonary disease. Am J Respir Crit Care Med 2005;171:972-977.

5. Gabriel R, Fiqueiredo D, Jacome C, et al.: Day-to-day living with severe chronic obstructive pulmonary disease: Towards a family-based approach to the illness impacts. Psychol Health 2014;29:967-983.

6. Shankar A, McMunn A, Banks J, Steptoe A: Loneliness, social isolation, and behavioral and biological health indicators in older adults. Health Psychol 2011;30:377-385.

7. Rennard S, Decramer M, Calverley PMA, et al.: Impact of COPD in North America and Europe in 2000: Subjects' perspective of Confronting COPD International Survey. Eur Respir J 2002;20:799-805.

8. Ahmadi Z, Sandberg J, Shannon-Honson A, et al.: Is chronic breathlessness less recognized and treated compared with chronic pain? A casebased randomised controlled trial. Eur Respir J 2018;52:1800887.

9. Celli B, Blasi F, Gaga M, et al.: Perception of symptoms and quality of lifecomparison of patients' and physicians' views in the COPD MIRROR study. Int J Chron Obstruct Pulmon Dis 2017;12:2189-2196.

10. Hutchinson A, Pickering A, Williams $P$, et al.: Breathlessness and presentation to the emergency department: A survey and clinical record review. BMC Pulm Med 2017;17:53.

11. Luckett $T$, Phillips J, Johnson $M$, et al.: Insights from Australians with respiratory disease living in the community with experience of selfmanaging through an emergency department 'near miss' for breathlessness: A strengths-based qualitative study. BMJ Open 20177: e017536. 
12. Australian Bureau of Statistics (ABS): 2016 Census: Australian Bureau of Statistics. https://www.abs.gov.au/websitedbs/censushome.nsf/home/ 2016 (Last accessed March 16, 2020).

13. Bestall J, Paul E, Garrod R, et al.: Usefulness of the Medical Research Council (MRC) dyspnoea scale as a measure of disability in patients with chronic obstructive pulmonary disease. Thorax 1999:54:581-586.

14. Norweg AM, Whiteson J, Demetis S, Rey M: A new functional status outcome measure of dyspnea and anxiety for adults with lung disease: The dyspnea management questionnaire. J Cardiopulm Rehabil 2006;26:395-404.

15. Norweg A, Pengsheng N, Garshick E, et al.: A multidimensional computer adaptive test approach to dyspnea assessment. Arch Phys Med Rehabil 2011;92:1561-1569.

16. Passmore R, Durnin JVGA: Human energy expenditure. Physiol Rev 1955 35:801-840

17. Eysenbach G: Improving the Quality of Web Surveys: The Checklist fo Reporting Results of Internet E-Surveys (CHERRIES) J Med Internet Res 2004;6:e34.

18. Johnson M, Bowden J, Abernethy AP, Currow DC: To what causes do people attribute their chronic breathlessness? A population survey. J Palliat Med 2012;15:744-750.

19. Smith AK, Currow DC, Abernethy AP, et al.: Prevalence and outcomes of breathlessness in older adults: A national population study. J Am Geriatr Soc 2016;64:2035-2041.

20. Maslow AH: Motivation and Personality. New York, NY: Harper and Row 1954.

21. Tieck K, Mackenzie L, Lovell M: The lived experience of refractory breathlessness for people living in the community. Br J Occupat Ther 2019;82:127-135.

22. Stalvey BT, Owsley C, Sloane ME, Ball K: The Life Space Questionnaire: A measure of the extent of mobility of older adults. J Appl Gerontol 1999;18: 460-478.

23. Currow DC, Dal Grande E, Ferreira D, et al.: Chronic breathlessness associated with poorer physical and mental health-related quality of life (SF12) across all adult age groups. Thorax 2017;72:1151-1153.

24. Stall NM, Savage RD, Rochon PA: Loneliness in older adults. CMAJ 2019; 191:E476.

25. Ekström M, Johnson MJ, Taylor B, et al.: Breathlessness and sexual activity in older adults: The Australian Longitudinal Study of Ageing. NPJ Prim Care Respir Med 2018;28:20.

26. Steinhauser KE, Christakis NA, Clipp EC, et al.: Factors considered important at the end of life by patients, family, physicians, and other care providers. JAMA 2000;284:2476-2482.

27. Hordern AJ, Currow DC: A patient-centred approach to sexuality in the face of life-limiting illness. Med J Aust 2003;179:S8-S11.

28. Matzo ML, Pope $\mathrm{E}$, Whalen J: An integrative review of sexual health issues in advanced incurable disease. J Palliat Med 2013;16:686-691.

29. Leung MW, Goldfarb S, Dizon DS: Communication about sexuality in advanced illness aligns with a palliative care approach to patientcentered care. Curr Oncol Rep 2016;18:11

30. Lindau ST, Surawska H, Paice J, Baron SR: Communication about sexuality and intimacy in couples affected by lung cancer and their clinical-care providers. Psychooncology 2011;20:179-185.
31. Sporn NJ, Smith KB, Pirl WF, et al.: Sexual health communication between cancer survivors and providers: How frequently does it occur and which providers are preferred? Psychooncology 2015;24:1167-1173.

32. Sanchez VV, Zhou ES, Bober SL: Management of sexual problems in cancer patients and survivors. Curr Probl Cancer 2013;37:319-352.

33. Ekström $M$, Chang $S$, Johnson $M J$, et al.: Low agreement between mMRC rated by patients and clinicians: Implications for practice. Eur Resp J 2019; 54:1901517.

34. Hutchinson A, Barclay-Klingle N, Galvin K, Johnson MJ: Living with breathlessness: A systematic literature review and qualitative synthesis. Eur Resp J 2018:51:1701477.

35. Morgan DD, White KM: Enabling participation in meaningful and essentia occupations in end-of-life care. In: Soderback I (ed): International Handbook of Occupational Therapy Interventions. Switzerland: Springer, 2015, pp. 787-796.

36. Saracino A, Weiland TJ, Jolly B, Dent AW: Verbal dyspnoea score predicts emergency department departure status in patients with shortness of breath. Emerg Med Australas 2010;22:21-29.

37. Currow DC, Clark K, Mitchell GK, et al.: Prospectively collected characteristics of adult patients, their consultations and outcomes as they report breathlessness when presenting to general practice in Australia. PLoS One 2013;8:e74814.

38. von Winckelmann K, Renier W, Thompson M, et al.: The frequency and outcome of acute dyspnoea in primary care: An observational study. Eur J Gen Prac 2016;22:240-246.

39. Frese T, Sobeck C, Herrmann K, et al.: Dyspnea as the reason for encounter in general practice. J Clin Med Res 2011;3:239-246.

40. Higginson IJ, Bausewein C, Reilly CC, et al.: An integrated palliative and respiratory care service for patients with advanced disease and refractory breathlessness: A randomised controlled trial. Lancet Respir Med 2014;2: 979-987.

41. Kimberlee R: What is social prescribing? Adv Soc Sci Res J 2015;2:102-110.

Cite this article as: Kochovska $S$, Chang $S$, Morgan DD, Ferreira $D_{\text {, }}$ Sidhu M, Saleh Moussa R, Johnson MJ, Ekström M, Currow DC (2020) Activities forgone because of chronic breathlessness: a cross-sectional population prevalence study, Palliative Medicine Reports 1:1, 166-170, DOI: $10.1089 / p m r .2020 .0083$.

Abbreviations Used
DMQ $=$ Dyspnea Management Questionnaire
DMQ-CAT $=$ Dyspnea Management Questionnaire Computer
Adaptive Test
mMRC $=$ modified Medical Research Council

\section{Publish in Palliative Medicine Reports}

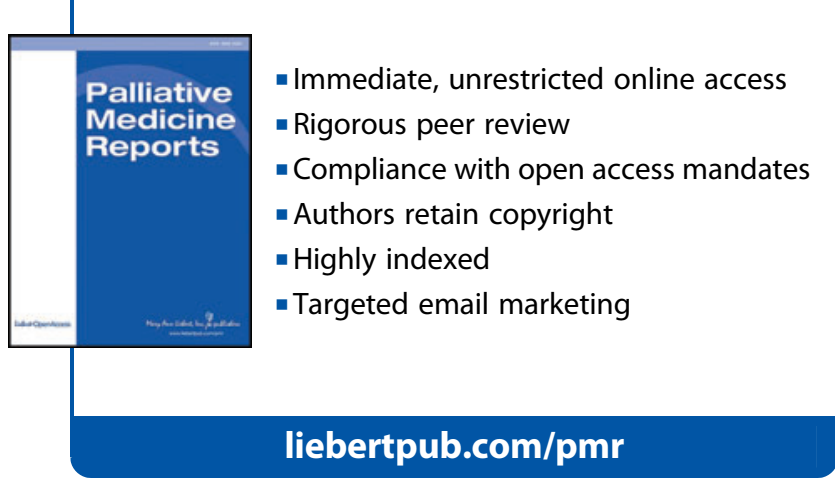

